\title{
A FOOTnote to the jers: The Russian trochee-iamb shift and cognitive linguistics
}

\author{
Tore Nesset, UiT The Arctic University of Norway
}

\begin{abstract}
:
This article explores the fall and vocalization of the jers, making five claims. First, it is shown how the jer shift can be analyzed in terms of a trochaic pattern, whereby a jer fell unless it headed a foot. Second, the foot-based approach is argued to be superior to the traditional counting mechanism postulated for the jer shift in that the foot-based approach avoids ad hoc stipulations and facilitates cross-linguistic comparison. Third, the present study relates the fall of the jers to a trochee-iamb shift in Russian prosody; a few generations after the jer shift was completed, an iambic pattern was introduced through the emergence of akan'e. Fourth, it is proposed that Contemporary Standard Russian may be a "switch language", i.e. a language where productive processes are sensitive to both trochees and iambs. Last but not least, the present study analyzes prosodic change from the point of view of cognitive linguistics (the Usage-Based Model), and shows that this framework offers a straightforward account of the jer shift.
\end{abstract}

Keywords: jers, prosody, vowel reduction, stress, trochee, iamb, Old Rusian, Contemporary Standard Russian

\section{Introduction}

The fall and vocalization of the jers, the vowels deriving from Proto-Slavic short / $\mathbf{l}$, $\breve{\mathrm{u}}$, is one of the pivotal changes in the history of Russian and other Slavic languages. The present study aims at situating this shift as part of a larger picture, which I refer to as the "trochee-iamb shift". It is argued that the jer shift involved trochaic feet, but that iambs were introduced into the prosodic system with the emergence of akan'e a few generations after the completion of the jer shift. After a brief analysis of jers in terms of trochaic feet in section 1 , sections 2 and 3 show that cognitive linguistics (the Usage-Based Model) provides a straightforward account of the jer shift. In sections 4 and 5, I explore Contemporary Standard Russian (henceforth CSR) and advance the idea that CSR may be a "switch language" involving both

\footnotetext{
* I would like to thank the members of the research group CLEAR (Cognitive Linguistics: Empirical Approaches to Russian) at UiT The Arctic University of Norway for commenting on an earlier version of this article. Thanks also to Martin Krämer for discussing issues of prosody and phonological theory with me. Finally, I am indebted to the editor and anonymous referees of JSL for valuable input.
} 
trochaic and iambic feet in ways that resemble Australian languages such as Yidiny and Wargamay. ${ }^{1}$ The contribution of the article is summarized in section 6 .

\section{Jers and trochaic feet}

In what follows, we will see that trochaic feet facilitate a straightforward and insightful account of Havlik's law for the fall and vocalization of the jers.

After the collapse of phonemic length in Common Slavic, the jers may be analyzed as lax vowels in Early Old Rusian (Andersen 1996: 15-16, 1998: 432), which would entail centralized articulation and short duration (Laver 1994: 417, see also Jakobson and Halle 1964: 97). ${ }^{2}$ Shevelov (1965: 432) talks about a "certain centralization of the articulation" and characterizes the "articulation [of the jers] as a whole" as "more slackened". Evidence for an analysis of the jers as lax vowels comes from the subsequent vocalization of jers across Slavic. In many varieties, jers developed into schwa, which is natural if one assumes that the jers were lax vowels. Even in varieties such as Russian where the jers vocalized to /e, o/, the lowering from high to mid vowels involves a movement away from the upper periphery towards the center of the vowel space, which seems natural under the assumption that the jers were lax vowels. In phonetic terms, the jers were probably shorter than the other lax vowels, since high vowels generally have shorter inherent duration than non-high vowels (Laver 1994: 435 and references therein). In other words, we are dealing with the two lax vowels with the shortest inherent duration, which were most vulnerable to elision (Jakobson 1963/1971: 673). In this sense the label "reduced vowel", which is often used, especially in the Russian tradition, seems appropriate and will be employed in the following.

Whatever analysis one assumes for the phonological and phonetic status of the jers, their fate cannot be predicted from their segmental makeup alone, since some jers vocalized, while others fell. As traditionally presented in textbooks and handbooks, Havlik's law for the fall and vocalization of the jers involves a counting mechanism, whereby jers are numbered from right to left. ${ }^{3}$ Consider the following examples (see Kiparsky 1963: 94) where subscript indices indicate the numbering and a phonemic representation of the corresponding CSR word is given after the arrow: 4

\footnotetext{
${ }^{1}$ In my analysis of modern Russian, I limit myself to Contemporary Standard Russian, since the facts about prosody in general and vowel reduction in particular are substantially different in the dialects of modern Russian.

2 For the purposes of this article, I use the term "Old Rusian" (with one s), which alludes to Rus', to denote the ancestor of today's Belarusian, Ukrainian and Russian languages. The traditional term "Old Russian" (with double s) is a misnomer, since we are dealing with the ancestor of not only Russian, but of all East Slavic languages.

${ }^{3}$ A detailed overview of the treatment of Havlik's law in various textbooks is beyond the scope of the present study. An extensive overview can be found in Kiparsky 1963: 93-99, which is available in English translation (Kiparsky 1979). Other textbooks in English with chapters on the jers include Vlasto 1986: 50-53 and, more recently, Nesset 2015: 246-250.

${ }^{4}$ As is customary in Slavic linguistics, I will use the Cyrillic symbols $\mathrm{b}$ and $\mathrm{b}$ to represent the front and back jers. Notice that the term "jer" is sometimes used about vowel $\sim$ zero alternations in modern Russian words, such as norvežec $\sim$ norvežca 'Norwegian (Nominative $\sim$ Genitive)' (see e.g. Yearley
} 
(1) a. $\mathrm{lb}_{3} \mathrm{Stb}_{2} \mathrm{Cb}_{1} \rightarrow \mathrm{l}^{\prime} \mathrm{st}$ 'ec 'flatterer'

b. otъ oxodb $_{1}$ niku $\rightarrow$ otxodn'iku 'hermit (dative sg)'

c. $\mathrm{Sъ}_{2} \mathrm{žb}{ }_{1}$ gla $\rightarrow$ sožgla 'she burned'

d. Sъ $\mathfrak{1}_{1}$ na $\rightarrow$ sna 'dream (genitive singular)'

In (1a), the first and third jers fell, while jer number two vocalized to /e/, as can be seen from the modern Russian equivalent /l'st'ec/. Examples (1b-d) illustrate the counting mechanism in words that contain both jers and non-jer vowels. Of particular interest is (1b); in order to predict the right outcome, we have to restart the counting of jers after the non-jer vowel in the suffix.

On the basis of examples like these, we can formulate the traditional version of Havlik's law as follows:

(2) a. Number the jers from right to left.

b. Restart the numbering from non-jer vowels.

c. Jers with odd numbers are in weak position and fall.

d. Jers with even numbers are in strong position and vocalize. ${ }^{5}$

I will use the traditional term "sound law" to refer to Havlik's law, although strictly speaking it is only parts $(2 \mathrm{c}-\mathrm{d})$ that describe language change. The statements in (2a-b) concern the synchronic description of jers in Late Common Slavic and Early Old Rusian. Although there are a number of well-known deviations from Havlik's law, such as so-called CЪRC and CRЪC groups, tense jers, certain consonant clusters and analogical leveling (see e.g. Kiparsky 1963), the traditional sound law enables us to predict the right outcome in most cases.

While (2) works well as a descriptive summary of the linguistic facts at hand, it is problematic from the perspective of theoretical linguistics, since it merely approximates what Chomsky (1964: 29) has termed "observational adequacy". I will focus on two important issues. First of all, whatever was going on in the minds of the speakers of Old Rusian at the time of the fall of the jers, it is clear that they were not counting their jers from right to left. In other words, the statements in (2a-b) cannot aspire to psychological realism, and in that sense has limited explanatory power. Second, as pointed out by Kavitskaya (2002: 118) the statement in (2b) appears as a mere stipulation, which is completely independent of the main counting mechanism in $(2 a)$.

The question now arises as to whether it is possible to come up with a more explanatory version of the sound law, where the effect in (2b) would not stand out as an ad hoc stipulation. I argue that a first step in the right direction is to relate the jers to foot structure and assume that Old Rusian had trochaic feet, i.e. disyllabic units with the head to the left. While this is not a new idea (see Bethin 1998: 213,

1995). For the purposes of this article I will only be interested in the jers in Common Slavic and Old Rusian, and vowel $\sim$ zero alternations in modern Russian will not be explored.

${ }^{5}$ For the purposes of the present study, I use the traditional term "vocalization" about the process whereby jers become non-reduced vowels. Arguably, it is oxymoronic to say that jers vocalize ("become vowels") since they already are vowels. 
Lavitskaya and Kabak 2014: 381), many properties of the system have not been worked out in detail.

The notion of "foot" is strongly associated with the analysis of stress systems, so it is worth pointing out that the feet proposed in the present study are not devised in order to accommodate stress in Old Rusian, although-as will be shown below-there is a non-trivial relationship between the proposed feet and stress. The purpose of the foot structure to be explored in the following is to tackle the behavior of reduced vowels. As shown in (1) and (2), the jer shift followed a rhythmic principle, insofar as every second jer underwent vocalization. Since we are dealing with a rhythmic grouping of syllables, the term "foot" is appropriate and will be used in the following, although some researchers prefer to talk about "disyllabic units" instead of "trochaic feet" (see Timberlake 1983a: 207, Kavitskaya 2002: 119).

In order to see what feet were acceptable in Old Rusian before the fall of the jers we need to consider the four logically possible combinations of non-jer vowels (represented as V) and jers (represented as \):
a. Vъ (e.g. domъ 'house')
b. ${ }^{*} \mathrm{bV}($ not attested)
c. ЂЪ (e.g. şnъ 'dream')
d. VV (e.g. two last syllables in otъxodьniku 'hermit (dative sg)')

As shown, I propose that all possible combinations yield legitimate feet, except $\mathrm{bV}$, which is accordingly supplied with an asterisk in (3b). This is a natural consequence of the assumption that Old Rusian had trochaic feet (with the head to the left). Assuming the jers were reduced vowels, it would be unnatural for a reduced vowel to head a foot where the other syllable was an unreduced non-jer vowel. Such a foot would be typologically very marked, since a reduced vowel would occupy a prosodically more prominent position than a full vowel. ${ }^{6}$ In other words, what I suggest is that a jer could only be the head of a foot if the other syllable also was a jer (3c). I hasten to add that even though $\mathrm{bV}$ is an illegitimate foot, such syllable combinations are attested in the language. However, as will be shown below, words like $5 z_{1} n a$ 'dream (genitive singular)' in (1d) do not allow us to construct any feet, and both vowels are therefore left unfooted. Importantly, a word does not need to contain a foot in order to be well formed.

Let us consider again the examples from (1) to see how feet were built in Old Rusian:
a. $\quad \mathrm{l}_{3} \mathrm{stb}_{2} \mathrm{Cb}_{1}$ 'flatterer': $\mathrm{b}_{3}\left(\mathrm{~b}_{2} \mathrm{~b}_{1}\right)$

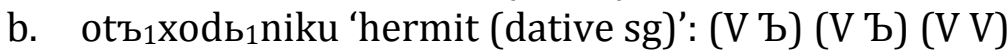
c. $\mathrm{S}_{2} \mathrm{Z} \mathrm{b}_{1}$ gla 'burned': $\left(\mathrm{b}_{2} \mathrm{~b}_{1}\right) \mathrm{V}$
d. Sъ ${ }_{1}$ na 'dream (genitive singular)': $\mathrm{b}_{1} \mathrm{~V}$

\footnotetext{
${ }^{6}$ Evidence for the idea that certain vowels (in our case the jers) are less optimal prosodic heads than other vowels comes from languages with so-called quality-sensitive stress. Kenstowicz (1997: 158) shows that for a number of languages "lower vowels are more optimal stress-bearing units than higher vowels [...] and peripheral vowels are more optimal than central vowels". Crosswhite (2001: 39) applies this idea to vowel reduction in Slavic. See also Gouskova 2003 for relevant discussion.
} 
In (4a), we build trochaic feet from the right word boundary. The leftmost jer is left unfooted, since we need two syllables in order to form a foot. Example (4b) allows us to build three feet. Notice that this is an example where the traditional version of Havlik's law would force us to restart the counting of jers, as shown in the ad hoc stipulation in (2b). If we assume trochaic feet, on the other hand, no additional stipulations need to be made; we build feet from the end of the word, and the result is two legitimate feet. Example (4c) is slightly more complicated. Here, we need to leave the word-final non-jer vowel unfooted in order to avoid forming an illegitimate $\mathrm{bV}$ foot. This follows directly from the ban of the $\mathrm{bV}$ foot and represents the only way to form legitimate feet from a $\mathrm{b} \mathrm{b} V$ string. ${ }^{7}$ In other words, no additional stipulations need to be made, except for the general requirement that disyllabic trochees are built whenever possible. Example (4d) illustrates that a word can be well formed even if it does not contain a foot. The sequence $\mathrm{b}_{1} \mathrm{~V}$ in (4d) does not make it possible to build a foot, and the entire word is left unfooted. ${ }^{8}$

Before we proceed, a note on feet of the VV type is in order. Examples such as $\left(\right.$ ot $\left._{1}\right)\left(\mathrm{xodb}_{1}\right)($ niku $)$ in $(4 \mathrm{~b})$ suggest the need to assume feet of this type, since the VV foot at the end facilitates a straightforward analysis in terms of three regular feet built from the right edge of the word. Whether words with no jer vowels (e.g. more 'sea') were parsed into feet, remains an open question of no consequence for the present study.

With the proposal that Old Rusian had right-aligned trochaic feet in place, we are in a position to formulate a new version of Havlik's law:

(5) a. A jer undergoes vocalization if it is the head of a foot.

b. All other jers fall.

The examples from (4) illustrate how this works. In $\mathrm{lb}_{3}\left(\mathrm{stb}_{2} \mathrm{Cb}_{1}\right)$ jer number two is the head, and therefore vocalizes, while the other jers fall. In $\left(\operatorname{otz}_{1}\right)\left(\operatorname{xodb}_{1}\right)(n i k u)$ no

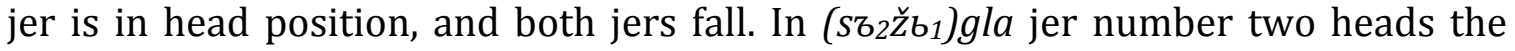
foot and thus survives, while the other jer disappears. Finally, the single jer in $s z_{1} n a$ is left unfooted, and therefore falls.

\footnotetext{
${ }^{7}$ It is worth pointing out that non-exhaustive parsing, i.e. the state of affairs whereby some syllables of a word are not part of a foot, is widespread across the languages of the world (see e.g. McCarthy and Prince 1993, Hayes 1995: 308-309, Ito and Mester 2003). For instance, footless syllables have been assumed for the analysis of ternary stress patterns (see Rice 2007).

8 This claim has important theoretical implications, since it goes against the idea of "headedness" (Selkirk 1995), which entails that all prosodic words in all languages contain at least one foot. While a critical evaluation of the universality of headedness is beyond the scope of the present study, two remarks are in order. First, the very idea of absolute universals, i.e. categories found in all languages with no exceptions, has come under attack in recent years, and Evans and Levinson (2009: 429) argue that there are "vanishingly few universals of language in the direct sense that all languages exhibit them". Second, in phonology even the universality of the most well established prosodic constituent, the syllable, has been disputed. For instance, Hyman (2008: 113) shows that the Nigerian language Gokana "fails to show any evidence of syllables in its segmental or prosodic phonology or morphology", and Labrune (2012) makes the same claim for Japanese. In view of this, it should not be too surprising to find languages where some words are not parsed into feet.
} 
Is there any independent evidence for an approach to the jer shift in terms of trochaic feet? I would like to point to both typological and Slavic evidence. As for typology, the trochaic system described above is of a cross-linguistically widespread type of syllabic trochees assigned from right to left (see Hayes 1995: 202-203). In other words, an approach in terms of feet allows us to situate Late Common Slavic/Early Old Rusian prosody in a typology of prosodic systems, whereas the traditional counting system does not facilitate such cross-linguistic comparison.

As for Slavic evidence, the stress system of Old Rusian provides an argument in favor of the proposed foot structure, insofar as it enables us to clarify an important constraint on stress placement in Old Rusian. While the foot structure explored above is not based on an analysis of stress, the proposed feet and stress interact in non-trivial ways. To see this, a brief exposition of the Old Rusian stress system is required.

The Old Rusian stress system was in the process of changing and involved dialect differences, but it seems clear that two subsystems for stress assignment were operative, so-called autonomous and automatic stress. The term "stress" must be used with caution. The two types of "stress" were phonetically different and could produce minimal pairs (e.g. piti 'drink (infinitive)' with autonomous stress and piti 'drink (participle)' with automatic stress, Zaliznjak 1985: 120), so it stands to reason that the system was at least in part tonal (Jakobson 1963/1971), a situation that may have lasted until the 1300s, when the two subsystems merged (Zaliznjak 2015: 11).

Numerous words received autonomous stress, which was unpredictable and could fall on any syllable of the word. Thus, autonomous stress was lexically specified and no phonological rule involving foot structure could account for its placement in the word (Zaliznjak 2015: 10 and 12). Since there is no need to invoke (trochaic) feet in order to account for autonomous stress, autonomous stress does not offer any direct evidence for foot structure.

Words that were not lexically specified for autonomous stress received automatic stress, which fell on the first syllable of the phonological word and presumably had a different phonetic realization than autonomous stress (Jakobson 1963/1971, Zaliznjak 1985: 120). Unlike lexically specified autonomous stress, automatic stress was purely phonological, insofar as its locus was predictable from the sound shape of the phonological word (its left edge). Thus, the accusative singular of golova 'head' would receive automatic stress on the first syllable. However, if the prosodic word included proclitics, automatic stress would fall on the first proclitic (e.g. ná golovu, né na golovu, í ne na golovu, etc., Zaliznjak 2015: 10). We do not need to invoke feet in order to specify the locus of automatic stress at the left edge of the prosodic word, so once again the stress system does not present us with substantial empirical arguments for foot structure.

Even if the facts reviewed above do not motivate an analysis of Old Rusian stress in terms of feet, stress indirectly provides an argument in favor of the foot structure proposed for the analysis of jers, since this foot structure enables us to capture an important generalization about stress placement. It is often said that stress cannot fall on a "weak" jer, i.e. a jer that receives an odd number according to the traditional version of Havlik's law. As pointed out by Blumenfeld (2006: 192), 
this is true of autonomous stress, since a sound change known as the "neoacute" moved stress from a weak jer to the preceding syllable (Timberlake 1983a-b; Kavitskaya 2002, 2005). However, weak jers received automatic stress if they happened to be in the first syllable of a phonological word without lexical stress. For example, Tbxverrb, the medieval name of the city Tver', had automatic stress on the weak jer in the first syllable (see Blumenfeld 2006: 193). The foot structure proposed in this article enables us to generalize the statement about unstressability of jers so as to cover both automatic and autonomous stress:

\section{(6) A jer at the right edge of a foot could not carry stress.}

In Tbxverrb, the analysis proposed in the present article yields the following foot structure: $\mathbf{b}(\mathrm{e}$ b). While the unfooted jer in the beginning of the word could receive automatic stress, the footed jer at the end of the word could not receive any kind of stress-neither automatic, nor autonomous.

Further evidence for the foot structure proposed in the present study comes from other examples of language change involving trochaic feet. The jer shift in Old Rusian is part of a larger picture, viz. compensatory lengthening processes that took place across the Slavic area in Late Common Slavic times (Timberlake 1983a-b, Kavitskaya 2002, 2005). As pointed out by Jakobson (1963/1971: 673), jers were particularly vulnerable for deletion in word-final position, and when jers were deleted, the preceding vowel underwent lengthening, which had different consequences in different Slavic languages. Kavitskaya $(2002,2005)$ analyzes this insightfully as the phonologization of phonetic duration. Vowels in open syllables are generally phonetically longer than vowels in closed syllables. After the fall of the final jer in $S z_{2} n r_{1}$ 'dream', the second jer ended up in a closed syllable where it was unexpectedly long. On the basis of this unexpected long duration, speakers recategorized strong jers as "normal" non-jer vowels. The details of this process of compensatory lengthening are not crucial in the present context. What is important is the fact that a jer and a preceding syllable formed a disyllabic unit (Timberlake 1983a: 207), where the syllable to the left behaved as the head since it became longer at the expense of the following jer, which was reduced and fell. The fact that trochees are needed not just to accommodate the fall of the jers, but the much larger phenomenon of compensatory lengthening across Slavic, lends support to the analysis outlined in the present study.

At the same time, it is important to notice that trochaic feet do not represent the motivation for compensatory lengthening or the jer shift. Rather, disyllabic domains arose as a consequence of the elision of word-final jers and compensatory lengthening. The merit of the foot-based approach is that it facilitates a simple and insightful characterization of the environment of the jer shift. In particular, it is significant that the behavior of the jers in words with intervening non-jer vowels (e.g. otzixodbiniku 'hermit (dative sg)') and words with non-jer vowels at the end (e.g. Szina 'dream (genitive singular)') falls out as the consequence of natural 
principles for the construction of the feet rather than an additional ad hoc condition on the counting of jers from right to left. ${ }^{9}$

At the end of the exposition of the foot-based account, it is worth pointing out that there are aspects of the jer shift that are beyond the scope of prosodic analysis in terms of feet. A case in point is the so-called CЪRC and CRЪC groups, i.e. cases where a jer immediately precedes or follows a liquid consonant $\left(/ \mathrm{r}, \mathrm{r}^{\prime}, \mathrm{l}, \mathrm{l}^{\prime} /\right)$. In Old Rusian, jers vocalized in such groups regardless of the prosodic environment. In other words, the jers vocalized even if there was no jer in the following syllable, as illustrated by the following examples (see Shevelov 1965: 467-469):

\section{a. CЪRC $\rightarrow$ CORC: vb1rba $\rightarrow$ verba 'willow' \\ b. CRЪC $\rightarrow$ CROC: $\mathrm{kr}_{1} \mathrm{vi} \rightarrow$ krovi 'blood (Dative sg)'}

In both examples, the jers vocalized although they were not followed by a syllable containing a jer. However, although CЪRC and CRЪC groups behave differently, they do not call into question the fact that the vast majority of jers can be accounted for in terms of foot structure. In this sense, the CЪRC and CRЪC groups do not threaten the analysis sketched in the present paper, but they represent systematic exceptions that demand independent explanations. In view of the fact that lengthening may have been the motivation for the vocalization of jers in general, one might speculate that jers with adjacent liquid consonants in CЪRC and/or CRЪC groups were longer than weak jers, and therefore vocalized. At the same time it is possible that the vocalization of jers in CЪRC and CRЪC groups were part of a strategy for avoiding complex syllable onsets-if the jers had fallen in (7a-b), we would have ended up with /vrb/ and /krv'/ onsets (which are not attested in CSR, see Švedova (ed.) 1980: 65). However, in-depth analysis of CЪRC and CRЪC groups is beyond the scope of the present paper, which focuses on the main pattern whereby the fate of a jer can be predicted on the basis of the foot structure.

\section{Cognitive linguistics and synchrony: a usage-based approach to prosody}

In this section, I will show that the generalizations outlined in the previous section can be straightforwardly accommodated in cognitive linguistics (the Usage-Based Model). Cognitive linguistics is a cover term for a family of linguistic frameworks that share the fundamental assumption that language is deeply integrated with other psychological phenomena, rather than constituting an autonomous module of the mind in the sense of Fodor (1983) and Chomsky (1986). (For critical discussion of modularity, see Dąbrowska 2004, Feldman 2006 and Goldberg 2006). In Janda's (2010) formulation, "for a cognitive linguist, linguistic cognition simply is cognition". The main focus in cognitive linguistics has been on semantics and morphosyntax, but the Usage-Based Model (Langacker 1991 and 2000, Kumashiro 2000) is a

\footnotetext{
${ }^{9}$ Recall that $\left(\mathrm{otz}_{1}\right)\left(\mathrm{xodb}_{1}\right)($ niku) receives a straightforward parse where no additional assumptions have to be made, while $s z_{1} n a$ is left unfooted as a consequence of the ban on $\mathrm{bV}$ feet. Importantly, this ban is not an ad hoc stipulation in the sense that it is motivated by typological markedness. The traditional counting mechanism would not enable us to make explicit the relationship between typological markedness and the behavior of jers in words like $s z_{1} n a$.
} 
framework that enables the cognitive linguist to analyze phonological phenomena (see Nesset 2005 and 2008, and Nathan 2008: 152-154).

A fundamental property of the Usage-Based Model is that it takes a "bottomup" perspective on language (Langacker 2000). This means that the grammar of a language consists of generalizations over actual usage events (utterances) that leave traces in the speakers' processing system. As Dąbrowska (2004: 213) points out, every time a linguistic unit is accessed, "its representation is strengthened, or entrenched, so units which are accessed frequently become easier to activate". In this way, the grammar of a language (including its phonological system) "grows out" of language usage.

Figure 1 models the relationship between grammar and usage with regard to the prosodic system of Late Common Slavic and Early Old Rusian. The rectangles with rounded corners at the bottom represent three usage events concerning the words $l_{3} s t_{b} \mathrm{Cb}_{1}$ 'flatterer', sъnъ 'dream', domъ 'house', and otz ${ }_{1} x_{0}$ db $_{1}$ niku 'hermit (dative sg)'. As shown in the figure, speakers grouped the words in disyllabic units, which would become entrenched as the patterns were reinforced through repetition. This enabled speakers to form schemas, i.e. generalizations over usage events. The schemas are located in the mental grammar, which in the figure is represented as a rectangle with dashed lines. The grammar contains three schemas representing the three legitimate trochaic feet in Late Common Slavic and Early Old Rusian. Boldfaced vowels represent the head of a foot. The arrows that connect the schemas and the usage events represent categorization relations of the type Langacker (2008: 17) refers to as "instantiations". Instantiation relations hold between two compatible structures where one is more specific than the other; in the figure, the concrete words in the usage events are much more specific than the schemas in the grammar, which, for instance, do not contain any information about consonants. Instantiations illustrate the non-modularity of cognitive linguistics, insofar as instantiation relations are not limited to phonology or linguistics, but are used in forming all kinds of categories in cognition in general.

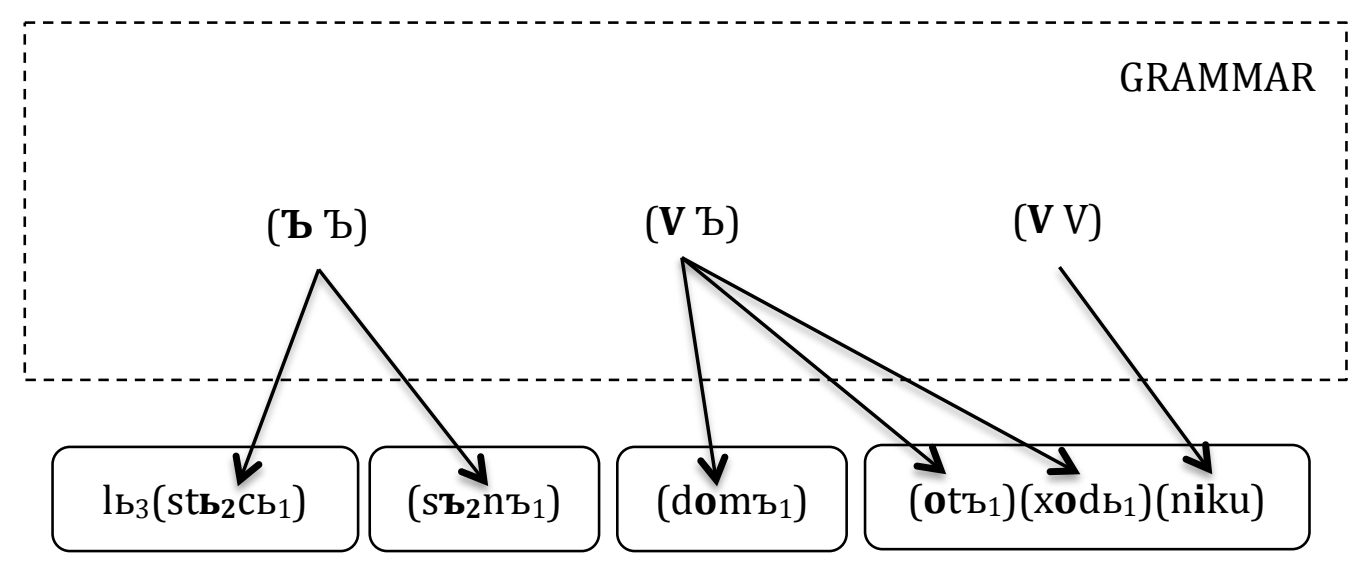

Figure 1: Schemas for trochaic feet in the Usage-Based Model

Figure 1 provides a simple illustration of how a grammar with trochaic feet may emerge through the categorization of usage events. Since the grammar contains schemas for all three legitimate feet, it gives an adequate account of the prosodic 
system. The grammar in Figure 1 is the mirror image of an approach in terms of Optimality Theory (Prince and Smolensky 2004), whereby a negative constraint, say, ${ }^{*} \mathrm{bV}$ would account for the relevant data. In cognitive linguistics, negative constraints are ruled out in principle; schemas are generalizations about what occurs in usage events, and it is therefore impossible to establish a schema for something that does not occur (Langacker 2000: 120, see also discussion in Taylor 2002: 250-252 and Nesset 2008: 17). In other words, whereas a grammar couched in Optimality Theory rules out certain structures and leaves everything else (even if it violates some constraints), the Usage-Based Model keeps track of what occurs and how entrenched it is in the grammar.

Figure 1 captures the relationship between patterns in the grammar (feet) and individual lexical items, but the figure is simplistic in a number of ways. For instance, the figure does not specify how learners of Old Rusian (before the jer shift) would figure out that there was a trochaic foot in, say, the nominative singular form $s ъ n z$ 'dream', but not in the genitive form sъna of the same noun. As mentioned in the previous section, I assume that the trochaic foot resulted from the shortening of the final jer in words like $s z n z$ and the compensatory lengthening of the previous syllable (Jakobson 1963/1971, Timberlake 1983a-b, Kavitskaya 2002, 2005). This, I speculate, created a prosodic disyllabic domain, which gradually became an entrenched pattern in the grammar. The trochaic pattern may then have been extended to the constellations $\mathrm{V} \mathrm{b}$ and $\mathrm{VV}$, but not to $\mathrm{bV}$, which, as argued above, did not lend itself to trochaic parsing, and in which no compensatory lengthening took place.

Although the simple format in Figure 1 accommodates the inventory of legitimate trochaic feet in Late Common Slavic and Early Old Rusian, the figure does not make explicit that feet are built from the right. In order to capture this generalization, we must focus on the right boundary of the feet, and characterize the feet with regard to what follows them. If we go back to (4) in the previous section, it becomes clear that we need to account for three kinds of situations. Figure 2 addresses these situations with special focus on the ( $\mathrm{b} \mathrm{b})$ foot type. First, a foot can be in word-final position, as illustrated by $l_{b_{3}}\left(s t b_{2} c_{b_{1}}\right)$ 'flatterer' in (4a). In Figure 2, the schema (ЪЪ)\# represents a word-final ( $\mathrm{b})$ foot. Second, $\left(d b_{2} n b_{1}\right)$ (nica) 'dawn' (Kiparsky 1963: 94) provides an example of a ( $\mathrm{b \zeta}$ ) foot that is followed by another foot. The schema $(\mathrm{bb})(\ldots$ takes care of this in Figure 2. The third situation we need to accommodate is when a foot is followed by an unfooted non-jer vowel, as in $\left(\mathrm{s}_{2} \mathrm{z}_{2} \mathrm{~b}_{1}\right)$ gla 'burnt' in (4c). This situation is represented as ( $\left.\mathrm{b} \mathrm{b}\right) \mathrm{V}$ in Figure 2. The figure includes schemas only for the ( $\mathrm{b})$ foot type, but a more complete grammar fragment would need to accommodate the other legitimate feet in the three positions we have just discussed. However, the simple sketch in Figure 2 is sufficient to illustrate two important points. First, the Usage-Based Model enables us to characterize the feet with regard to what follows them, and in this way makes it possible to capture that feet were right-aligned in Late Common Slavic and Early Old Rusian. Second, the figure shows that the three schemas discussed above are all instantiations of a more general schema, which is given at the top level in the figure. This schema generalizes over all positions and is therefore the same as the simple schema ( $\mathrm{b} \mathrm{b})$ from Figure 1. While the richer format in Figure 2 gives a more 
accurate picture of the situation, in the following we will stick to the simpler format in Figure 1, which is sufficiently precise for the purposes of the present study.

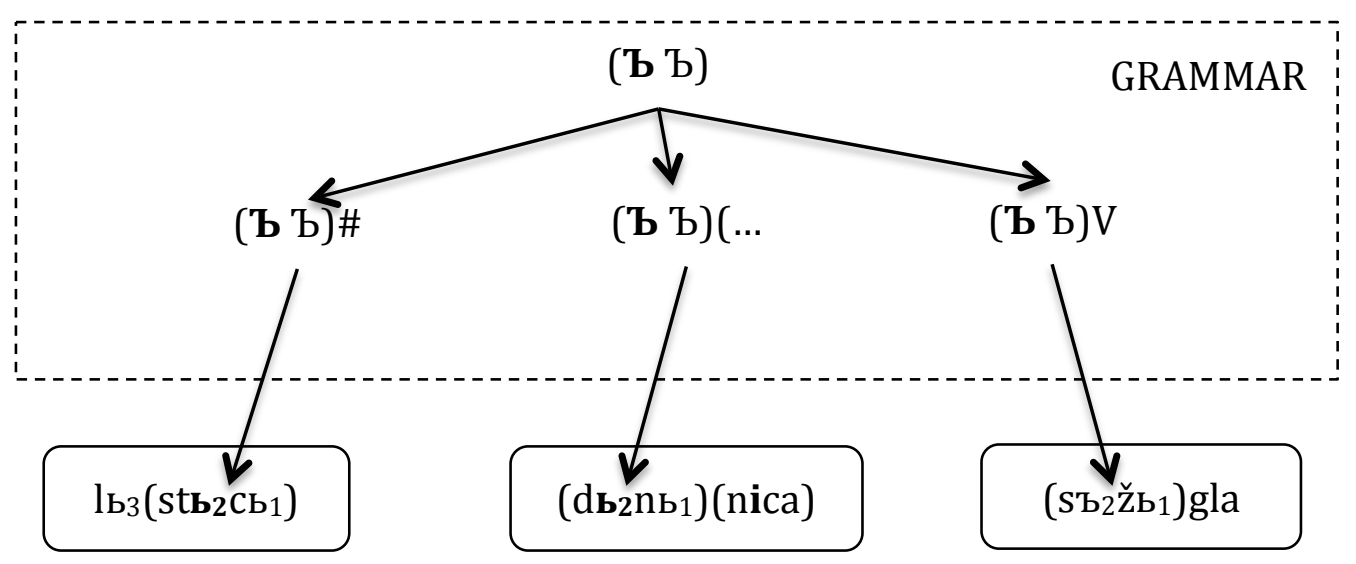

Figure 2: Right-aligned feet in the Usage-Based Model

Even though the Usage-Based Model takes a "bottom-up" perspective on language in the sense that usage events are primary, once the schemas in the grammar have emerged they can be used in a "top-down" fashion to categorize new linguistic items. By way of illustration, consider the situation in Figure 3, where a speaker who may not be familiar with $s b_{2} z ̌ b_{1} g l a$ 'she burned' considers different prosodic analyses of this word. In the bottom portion of the figure, two such competing analyses ("candidates") are given. These candidates are compared to the grammar, and the speaker attempts to find the candidate that is the best match for the grammar. As can be seen from the figure, the candidate to the left involves an instantiation relation to the leftmost schema, whereas the competing candidate is not connected to the grammar, because this candidate is not parsed into legitimate feet. Since the candidate to the left is licensed by the grammar, while the candidate to the right is not, the leftmost candidate is the winner. As a convention, the winning candidate is shaded.

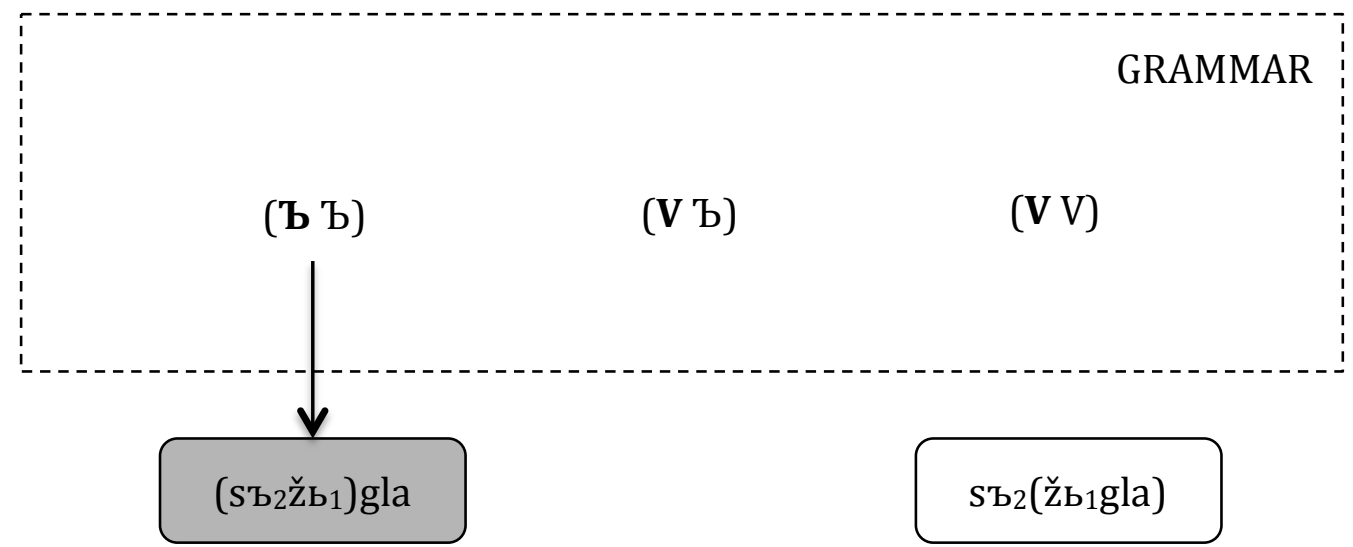

Figure 3: Competition between candidates in the Usage-Based Model

The simple examples in Figures 1 and 3 illustrate the interplay between lexicon and grammar. The grammar emerges on the basis of usage events, i.e. 
utterances of lexical items. The grammar can then be used to categorize new lexical items as shown in Figure 3, and these lexical items, once categorized correctly, reinforce the patterns in the mental grammar. Needless to say, this cyclic motion from usage events involving individual lexical items to schemas in the grammar and back again is a very crude model of language learning through language use. However, it is precise enough to show that cognitive linguistics is able to accommodate the prosodic system in terms of schemas and instantiation relations. Importantly, the analysis is well motivated from general cognitive principles, since the main machinery, schemas and instantiation relations, is recruited not only to accommodate linguistic categories, but for the analysis of categories in other realms of conceptualization as well (see e.g. Langacker 2008: 15-16 for discussion). The question now arises as to whether and how the analysis sketched above facilitates an account of language change as well. We turn to this question in the next section, which addresses the jer shift.

\section{Cognitive linguistics: a usage-based approach to the jer shift}

In the previous section we modeled language as the interaction between the lexicon (usage events involving individual lexical items) and the grammar (schemas over prosodic patterns). In order to analyze language change we must add a new dimension and consider the interaction between generations, speaker and addressee, caretaker and child. In the following, we will see that the jer shift can be accommodated in cognitive linguistics, and that the analysis I propose is consistent with the idea of phonologization of phonetic duration (Kavitskaya 2002). We will also see that the jer shift can be analyzed in terms of prosodic skewing (Salmons et al. 2012), which provides the opportunity for discussing the status of sound laws in the Usage-Based Model.

Figure 4 provides a very simple model of language change over three generations. ${ }^{10}$ Each generation has its own grammar, which for the purposes of illustration contains only one schema. This schema is connected to only one usage event involving one lexical item, the word for 'dream'. While this set-up is extremely simple, it suffices to illustrate the processes at work, i.e. how each generation constructs a new grammar based on the input of the previous generation (see Andersen 1973). In the first generation, the word is pronounced as [sъnъ], i.e. with two intact jers. This is compatible with a grammar containing the ( $\mathrm{b})$ trochee, i.e. a grammar of the kind we explored in the previous section. ${ }^{11}$

The rhythmic grouping of the two syllables into a trochaic foot creates an environment for strengthening the head jer and weakening the non-head jer. When the next generation forms its grammar based on the input from their caretakers

\footnotetext{
${ }^{10}$ Although I will refer to the stages in the development as "generations", there is nothing in the Usage-Based Model that prevents us from accommodating language change within generations as well.

${ }^{11}$ Note in passing that there is solid evidence from language acquisition that children are sensitive to and acquire prosodic patterns at an early stage. For instance, in an experimental study Jusczyk et al. (1993) show that by 9 months of age American children are sensitive to the predominant stress pattern in English.
} 
from generation 1 it is therefore likely that they will interpret the head jers as prosodically stronger than the non-head jers. Accordingly, they may start pronouncing the non-head jers as reduced. In order to show this in the figure, the non-head jers are represented with smaller font size. This, in turn, has consequences for the grammar, which emerges from usage events, and accordingly contains feet with reduced non-head jers.

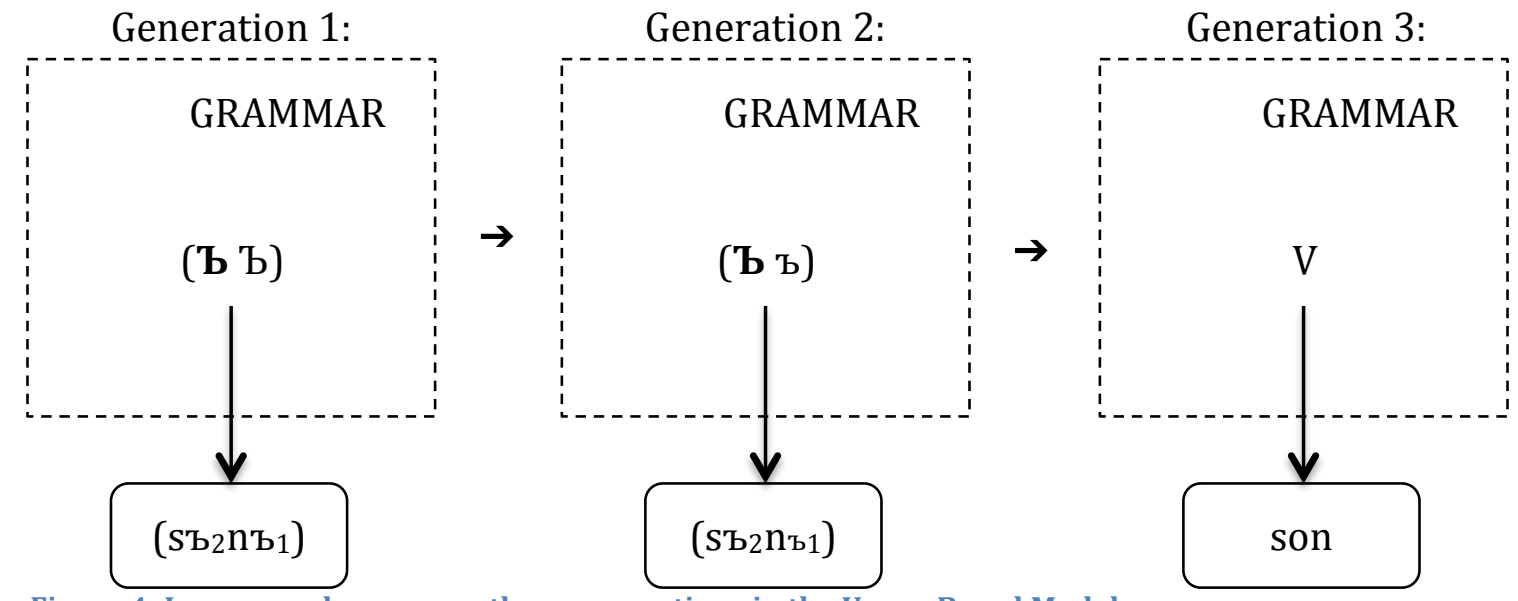

Figure 4: Language change over three generations in the Usage-Based Model

A gradual weakening of non-head jers over time can take place until some speakers do not categorize the non-head jers in the speech of their caretakers as independent vowels at all. This is shown in "generation 3" in Figure 4, where the non-head jer has disappeared. While the proposed account may seem speculative, it is compatible with Kavitskaya's (2002) idea of phonologization of phonetic duration, which was mentioned in section 1 . As pointed out by Kavitskaya, vowels in open syllables are generally phonetically longer than vowels in closed syllables. When speakers no longer categorize the non-head jer as a vowel, the strong jer ends up in a closed syllable, where it is unexpectedly long. On the basis of this unexpected long duration, speakers may categorize strong jers as "normal" non-jer vowels. The result would be a pronunciation of 'dream' as [son] with one closed syllable and no jers. This, in turn, would have consequences for the grammar. Since at this point there are no jers in the usage-events, there are no jers in the grammar. There are, furthermore, no trochaic feet in the grammar; the feet in the grammar emerge from the rhythmic grouping of jers together with non-jer vowels in the usage events, and when there are no more jers, there is no basis in the usage events for postulating feet in the grammar. In this sense, for the purposes of vowel reduction the jers drove the trochaic feet to their grave.

Before we leave the analysis of the jer shift, two theoretical points deserve mention. First of all, a fundamental problem in historical linguistics is how we can explain why certain sound changes continue in one direction over several generations. Salmons et al. (2012: 172) propose "prosodic skewing" as a possible explanation. They argue that child-directed speech "involves realizations of speech that parallel those found in prosodically prominent utterances", and suggest that 
this prosodic skewing towards prosodically more prominent realizations of vowels may affect the speech of younger generations. If a younger generation is exposed to less reduced vowels, it is likely that they would start pronouncing less reduced vowels themselves. In this way, over time one would expect language to develop so as to gradually lose (certain) reduced vowels. Needless to say, we know nothing about child-directed speech in medieval times, but the analysis of the jer shift outlined above is consistent with prosodic skewing as a driving force for sound change over several generations. The rhythmic grouping of vowels into trochaic feet created an environment that would enhance the differences between head jers and jers in non-head position. Given its prosodic prominence, the head position would facilitate the strengthening of a jer. In other words, we would expect head jers to be especially susceptible to prosodic skewing in child-directed speech. This skewing, in turn, would increase the contrast between head jers and jers in non-head position, and the non-head jers would be likely to undergo gradual reduction over time, as outlined in Figure 4. Notice that prosodic skewing is not at variance with Kavitskaya's analysis in terms of phonologization of phonetic duration. Prosodic skewing (which pertains to child-directed speech) and phonologization of phonetic duration (which concerns language structure) may be considered independent forces that pull in the same direction.

The second theoretical point that emerges from the proposed analysis of the jer shift regards the status of sound laws in the Usage-Based Model. The reader may have noticed that there is nothing corresponding directly to Havlik's law in the usage-based approach to the jer shift outlined above. Neither the traditional version of the sound law in (2c-d), nor the foot-based version in (5) is part of the usagebased account discussed in this and the previous section. I argue that sound laws cannot be represented in the Usage-Based Model-and that this is a good thing. The Usage-Based Model attempts to create (admittedly simple) models of speakers' mental grammars, i.e. aims at capturing the generalizations speakers make about their language. As pointed out by Andersen (1972: 11f.), sound laws such as Havlik's law are correspondences between different stages in the historical development of a language. Such stages may be centuries apart, as when we compare Late Common Slavic $s ъ n z$ to Contemporary Standard Russian son and conclude that a strong back jer in Late Common Slavic corresponds to /o/ in Contemporary Standard Russian. Such generalizations are made by linguists, and they are valuable in a scientific study of language, but they are not part of the generalizations native speakers make about their mother tongue, and since they are not part of the mental grammars of speakers, sound laws are outside the purview of the Usage-Based Model. I hasten to add that this does not make the Usage-Based Model irrelevant for historical linguistics; as I hope to have shown in this section, the Usage-Based Model enables us to juxtapose models for different generations and thus shed light on language change.

\section{A trochee-iamb shift in Russian prosody?}

In the preceding sections, we have focused on reduced vowels, known as jers, in Old Rusian. We now turn to reduced vowels in modern Russian, more precisely the 
phenomenon of akan'e. Although there are many differences between the jers and akan'e, it is fruitful to relate the phenomena, since in both cases we are dealing with lax vowels with short duration. I propose to connect the jer shift and akan'e through what I call the "trochee-iamb shift hypothesis". Two versions may be considered:

(8) The trochee-iamb shift hypothesis:

a. Strong version: Russian has undergone a shift from trochaic to iambic feet.

b. Weak version: Russian has undergone a shift from trochaic to iambic feet with regard to vowel reduction.

In short, I argue that the trochaic pattern described in the previous sections was replaced by an iambic system when akan'e emerged. The version in (8a) is stronger, since it makes a claim about the prosodic system in general, whereas the weaker version in (8b) restricts the trochee-iamb shift to a subsystem of Russian prosody, namely vowel reduction. In the following, it is argued that evidence for the weak version of the hypothesis comes from akan'e, the reduction of vowels in unstressed syllables. We will return to the strong version in section 5 , which is devoted to stress patterns in CSR. I will show that there is evidence for an analysis of CSR stress in terms of trochees. This goes against the strong version and supports the weak version of the trochee-iamb shift hypothesis.

While in the previous sections we have seen that reduced vowels (jers) in Late Common Slavic and Early Old Rusian involved trochaic feet, we now turn to vowel reduction in CSR, which has been analyzed in terms of iambic feet, thus suggesting a prosodic shift from trochees to iambs. ${ }^{12}$ In CSR, the /o/ phoneme is pronounced in three different ways according to its position in the word, as can be seen from words like gorodók 'small town', where /o/ in the first syllable is realized as [ə], the second $/ \mathrm{o} /$ as $[\Lambda]$, and the third, stressed /o/ as $[0]{ }^{13}$ In other words, in order to accommodate this vowel reduction pattern, we need to distinguish between three positions in the word:

(9) a. Stressed syllable (where /o/ is realized as [o])

b. First pretonic syllable (where $/ \mathrm{o} /$ is realized as $[\Lambda]$ )

c. Other unstressed syllables (where /o/ is realized as [ə])

While different vowels in different dialects have different realizations (see e.g. Crosswhite 2001), the fact that we need to distinguish between the three positions in (9) generalizes to all relevant varieties of modern Russian (the so-called "akajuščie govory"), as well as Belarusian. Since the vowel in the first pretonic

\footnotetext{
12 Halle and Vergnaud (1987) proposed iambic feet based on vowel deletion in words like zaëm 'loan' in Russian. When the vowel deletes (cf. genitive singular zájma), stress moves to the closest vowel to the left, which Halle and Vergnaud (1987) took to indicate that the two syllables that receive stress constitute an iambic foot. In view of the fact that this argument is based on a fairly marginal morphological pattern, I will not discuss it in the following (see, however, Revithiadou 1998: 122123 and Lavitskaya and Kabak 2014: 369 for critical discussion).

${ }^{13}$ Instead of $[\Lambda]$ other researchers prefer [a] or [e]. I will not discuss this issue, since the exact phonetic value of the vowel is not important for my line of argumentation. For discussion, the reader is referred to Barnes (2006: 49).
} 
syllable (the one immediately preceding the stressed syllable) is less reduced and longer than other unstressed vowels and hence more similar to stressed vowels, the first pretonic and the stressed syllable constitute a prosodic domain. ${ }^{14} \mathrm{We}$ may analyze gorodók as follows:

(10) gə(rıdók)

Here, parentheses represent the domain we are interested in. Since the domain is disyllabic and its head (the stressed syllable) is at the right margin, we may refer to it as an "iambic foot" (see e.g. Alderete 1995, Crosswhite 2001, Gouskova 2010). ${ }^{15}$ With the iambic foot in place, rules for vowel reduction (akan'e) can be formulated straightforwardly. For instance, in CSR unstressed /o/ and /a/ after hard consonants are realized as $[\Lambda]$ inside the foot, but as [ə] outside it. The iambic approach also comes with the advantage that it incorporates the Russian data into a general theory of prosodic domains, which facilitates typological comparison with other languages.

However, the situation is more complex than the simple representation in (10) suggests. In fact, there are three more positions that behave like the first pretonic syllable (see e.g. Matusevič 1976: 99-102, Barnes 2006: 49-51):

(11) a. Absolute word-initial position (with $[\Lambda]$ in e.g. ogorod 'garden')

b. Vowel hiatus (with $[\Lambda \Lambda]$ in e.g. sootnošenie 'correlation')

c. Phrase-final open syllables (with $[\Lambda]$ in e.g. zerkalo 'mirror' phrasefinally) ${ }^{16}$

Is it possible to give a unified account of all the positions where we find $[\Lambda]$, rather than [ə]? What does the first pretonic syllable have in common with the three positions in (11)? Barnes (2006: 51) argues that all positions are characterized by additional duration. In other words, vowels have longer duration in the relevant positions, and therefore the less reduced $[\Lambda]$ is pronounced instead of [ə].

On the face of it, Barnes' analysis seems to obviate the need for an iambic foot in Russian, since $[\Lambda]$ is not limited to the first pretonic syllable, but rather occurs in a number of different positions with additional duration (Lavitskaya and Kabak 2014: 380). Upon closer inspection, however, I argue that the facts lend support to an analysis in terms of an iambic foot. If we follow Barnes (2006) and accept that phonetic duration is the best predictor of the degree of vowel reduction in CSR, the question is how different durations are assigned to different unstressed syllables. Barnes (2006: 66) argues that the positions in (11) "receive additional duration for

\footnotetext{
${ }^{14}$ For some speakers, the first pretonic syllable may be longer than the stressed syllable. For discussion with references, see Gouskova 2010: 422-423.

${ }^{15}$ In a somewhat different analysis, Bethin (2006) attributes the special properties of the first pretonic syllable to tonal spreading from the following stressed vowel. However, as argued by Gouskova (2010), Bethin's analysis is not at variance with an iambic foot, since the iamb could be the domain of tonal spreading.

${ }^{16}$ I use Barnes' (2006) characterization of this position rather than Matusevič's (1976) "polnyj stil"'. However, both authors agree that the pronunciation of $[\Lambda]$ instead of $[\ni]$ is due to the longer duration of vowels in the relevant position.
} 
reasons not specific to the phonology of Russian". In other words, the additional duration in these positions are due to general phonetic properties that are not unique to the prosodic system of Russian. For this reason, these properties are not among the facts a child needs to learn when s/he acquires Russian, and these properties therefore need not be specified in the grammar of Russian. However, as pointed out by Barnes (2006: 66), the additional length of the first pretonic syllable is not due to general phonetic factors, but rather a property of "certain Slavic languages in particular". In other words, in order to acquire the prosody of Russian, children must figure out that the first pretonic syllable has longer duration than other unstressed syllables, and that the first pretonic syllable therefore is more similar to the stressed syllable than other unstressed syllables are. This is exactly the generalization that the iambic foot in (10) is designed to capture. I conclude that the additional duration of the first pretonic syllable is a language-specific property of CSR, which must be specified in the grammar of Russian, and that it lends support to iambic feet in CSR.

What are the diachronic implications of the analysis of CSR vowel reduction discussed above? If we accept that reduced vowels (jers) in Late Common Slavic and Early Old Rusian represented a trochaic pattern, the finding that CSR vowel reduction involves iambic feet suggests that a shift from trochees to iambs must have taken place. However, before we can accept the (weaker version of the) trochee-iamb shift hypothesis in (8), we must discuss chronology, motivation, and typological parallels of the proposed trochee-iamb shift.

With regard to chronology, the crucial question is when akan'e emerged. As is well known, this is a controversial issue in Slavic linguistics. ${ }^{17}$ Some scholars (including Shevelov 1965: 386-387) connect the emergence of akan'e to the development of /o/ and /a/ in Common Slavic and accordingly place the emergence of akan'e as far back as in the ninth or tenth centuries. What appears to be the majority view, however, is that akan'e took place in Old Rusian in the 1300s (see e.g. Knjazev 2000). Although an early emergence of akan'e cannot be excluded, the fact that the earliest textual evidence for akan'e comes from the late 1300s strongly speaks in favor of the 1300s as the time when akan'e arose (see e.g. Kiparsky 1963: 141, Galinskaja 2009: 147f.).

Exactly when the fall of the jers occurred is difficult to pinpoint. Since the jer shift affected all Slavic languages (with the possible exception of Polabian, Kiparsky 1963: 93), but changed different languages in different ways, it is clear that the jer shift was a long process that started in Late Common Slavic and was completed after the break-up of Slavic unity. It is believed that the jer shift started in the western part of the South Slavic area and gradually spread to the northeastern parts of the Slavic territory (Kiparsky 1963: 93, Shevelov 1965: 459, Isačenko 1970: 73). This makes it even harder to date the jer shift in East Slavic; since most written sources display some degree of Church Slavic/South Slavic influence, words showing reflexes of the jer shift may be due to Church Slavic spelling rather than East Slavic

${ }^{17}$ An extensive overview of the copious literature on the genesis of akan'e, which includes seminal works such as Jakobson 1929/1971, is beyond the scope of the present study. The reader is referred to Bethin (1998: 152-154, 2010: 12-13). 
pronunciation. While estimates vary somewhat, most scholars assume that the completion of the jer shift took place in Old Rusian (i.e. the northern part of the East Slavic area) between 1100 and 1250 (Kiparsky 1963: 98, Shevelov 1965: 459, Isačenko 1970: 74). If we accept these chronologies, it seems that the trochee-iamb shift was a swift change that took place over a few generations in the 1200 s and 1300s.

The question now arises as to why such a radical change in the prosody happened so fast. Is it possible to pinpoint any motivating factors? As Isačenko (1970: 90f.) aptly observes, the jer shift had "thoroughly shaken the whole morphophonemic system of East Slavic", and it represented the beginning of what he (1970: 122f.) refers to as "a period of trial and error". While Isačenko's focus is on morphophonology, it seems reasonable to say that the phonology proper was equally "shaken", given the far-reaching consequences the jer shift had for phonology (emergence of closed syllables, consonant clusters, devoicing of obstruents in word-final position etc.). In other words, it is not very surprising that this period of trial and error included radical changes in the prosody as well.

It is likely that language-external factors played an important role in the period of trial and error. It has been suggested that the emergence of akan'e was a substrate phenomenon (Shevelov 1965: 386-387, Veenker 1967: 25-35, Grenoble 2012: 584). While this is clearly speculative, it is not far-fetched, since we are dealing with a period of East Slavic expansion to the northeast into areas inhabited by peoples speaking other languages. Grenoble (2012: 584) lists the emergence of akan'e as a salient example of Finno-Ugric substrate influence on Russian, and Veenker (1967: 29-35) points to Moksha Mordvinian as the most likely Finno-Ugric language that may have motivated the emergence of akan'e in Russian.

A possible typological parallel involving a shift from trochees to iambs is French, although the foot structure of French is a controversial topic where a number of different analyses have been advanced (see Andreassen and Eychenne 2013 for discussion). It seems uncontroversial, however, that the development from Classical Latin to Old French involved considerable prosodic restructuring, which affected foot structure. Classical Latin had stress on the penultimate syllable if it was heavy, while stress otherwise fell on the antepenult. As pointed out by Jacobs (1992: 66), this situation can be analyzed in terms of a left dominant (i.e. trochaic) foot, which was quantity sensitive in the sense that the head was on the antepenult unless the penult was heavy. As a result of syncope and apocope, the prosodic system underwent radical restructuring, and Old French had stress on the final syllable (except when the word ended in a schwa). Jacobs (1992: 68) analyzes Old French as having a right dominant (i.e. iambic) foot at the end of the word. While the details are beyond the scope of the present study, the analysis suggests that Old Rusian is not unique in undergoing a prosodic shift of the type explored in the present study. Interestingly, the changes in the Old French phonological system may to some extent be motivated by a Celtic substrate (see Hock 1988: 481-485 for discussion), thus lending support to the idea of a substrate motivation for the trochee-iamb shift in Old Rusian outlined in the previous paragraph. 


\section{Contemporary Standard Russian - a "switch language"?}

In the previous section, we saw that there is support for the weaker version of the trochee-iamb shift hypothesis in (8), insofar as the iambic patterns for vowel reduction in CSR succeeded trochees for reduced vowels (jers) in Late Common Slavic and Early Old Rusian. The question now arises as to whether there is evidence for the stronger version of the hypothesis, i.e. whether the trochee-iamb shift pertains to the prosodic system in general, not just to vowel reduction. Although detailed discussion of the CSR stress system is beyond the scope of the present article, I will review some evidence from primary and secondary stress in favor of trochaic feet in CSR. This goes against the strong version of the trochee-iamb shift hypothesis, but at the same time paves the way for an interesting claim about CSR prosody. Taken together, the finding that vowel reduction is based on iambic feet while stress involves trochees suggests that CSR may be a "switch language", i.e. a language that employs different foot types for different purposes.

\subsection{Primary stress and trochaic feet}

Several scholars have analyzed the CSR stress pattern in terms of trochaic feet (see Halle and Idsardi 1996, Halle 1997, Revithiadou 1998, Mołczanow et al. 2013, and Lavitskaya and Kabak 2014). Simplifying somewhat, Halle and Idsardi (1996: 415) assume that words like koróva 'cow' have stress on both the stem and the ending in underlying representation (i.e. koróvá). The two underlyingly stressed syllables form a trochaic foot, and the underlying stress on the ending is deleted since it is not the head of the foot. Halle and Idsardi demonstrate that it is possible to describe the Russian stress system with the underlying representations and rules they assume, and their approach facilitates typological comparisons of stress systems across languages. However, whether the approach has any psychological reality (i.e. mirrors the mental grammars of native speakers of modern Russian) remains unclear since Halle and Idsardi essentially reconstruct the stress system from before the fall of the jers and transpose it to modern Russian (see Lavitskaya and Kabak 2014: 367-368 for critical discussion). In Halle's (1997: 309, see also Halle and Vergnaud 1987: 72) own words, "[t]he central features of the prosodic system of the Indo-European protolanguage [...] [have] survived essentially intact in many wellstudied I[ndo-]E[uropean] languages, Russian, Serbo-Croatian, Sanskrit and standard Lithuanian, for example".

Halle and Idsardi's approach to Russian stress is purely syntagmatic in the sense that the rules negotiate the accentual properties of a string of morphemes that constitute a word. A syntagmatic analysis along the lines of Halle and Idsardi represents a standard assumption in generative work on phonology, but recent years have witnessed a renewed interest in the relationship between phonological patterns and morphological paradigms (see e.g. Burzio 1996, Steriade 2000, Kenstowicz 2005, McCarthy 2005, Albright 2011, Bethin 2012a-b and references therein). In-depth discussion of the various theoretical proposals and the evidence that support them is beyond the scope of the present study. Instead, I will discuss data concerning stress in Russian that offer strong empirical evidence in favor of a paradigmatic approach. 
In CSR, stress relates to morphological paradigms in six different ways, which Zaliznjak 1967 refers to as stress patterns a-f. ${ }^{18}$ This is shown in Figure 5, where each cell stands for one of the four relevant subparadigms, viz. the nominative singular, the nominative plural, the oblique singular, and the oblique plural. I use "oblique" (obl) as a cover term for all cases that are different from the nominative. If a subparadigm receives stress on a syllable that is part of the stem ("stem stress"), the relevant cell is white, whereas subparadigms where stress falls on a syllable that belongs to the inflectional ending ("ending stress") is shaded. Two generalizations emerge from the figure. First, it is clear that for a given word stress is uniform within a subparadigm in the sense that stress has the same locus in all forms belonging to the relevant subparadigm. This is what Nesset (2015: 278) refers to as "subparadigm uniformity". Thus, if for the noun žená 'wife' we know that the dative plural has stress on the stem (žënam), we also know that the locative plural receives stress on the stem (žënax), since subparadigm uniformity entails that the locative and dative plural forms have the same stress placement.

a:

\begin{tabular}{|c|c|}
\hline N sg & N pl \\
\hline Obl & Obl \\
sg & pl \\
\hline
\end{tabular}

d:

\begin{tabular}{|c|c|}
\hline N sg & N pl \\
\hline Obl & Obl \\
sg & pl \\
\hline
\end{tabular}

b:

\begin{tabular}{|c|c|}
\hline N sg & N pl \\
\hline $\begin{array}{c}\text { Obl } \\
\text { sg }\end{array}$ & $\begin{array}{c}\text { Obl } \\
\text { pl }\end{array}$ \\
\hline
\end{tabular}

e:

\begin{tabular}{|c|c|}
\hline N sg & N pl \\
\hline Obl & Obl \\
sg & pl \\
\hline
\end{tabular}

C:

\begin{tabular}{|c|c|}
\hline N sg & N pl \\
\hline $\begin{array}{c}\text { Obl } \\
\text { sg }\end{array}$ & Obl \\
pl
\end{tabular}

f:

\begin{tabular}{|c|c|}
\hline N sg & N pl \\
\hline $\begin{array}{c}\text { Obl } \\
\text { sg }\end{array}$ & Obl \\
pl
\end{tabular}

Figure 5: Major stress patterns in Contemporary Standard Russian (letter codes from Zaliznjak 1967)

The second generalization that emerges from Figure 5 is that stress is closely related to grammatical meaning (inflectional features). Patterns $\mathrm{c}-\mathrm{f}$, which represent so-called mobile stress, i.e. patterns where part of the paradigm has stem stress and another part ending stress, illustrate this. In patterns c (mésto 'place', nominative plural mestá) and d (žená 'wife', nominative plural žëny) mobile stress creates an opposition between the singular and the plural. In pattern e (novost' 'news', genitive plural novostéj) mobile stress singles out the oblique cases in the plural, whereas in the smaller class of words like svečá 'candle' in pattern $\mathrm{f}$

\footnotetext{
${ }^{18}$ Admittedly, there are some minor patterns that involve less well behaved morphological splits in the paradigm, such as Zaliznjak's class $\mathrm{f}^{\prime}$ with stress retraction in the nominative plural and accusative singular (cf. ruká 'hand, arm' with nominative plural rúki and accusative singular rúku). However, since minor patterns like this concern small and closed classes of words, they do not jeopardize the general validity of a paradigmatic approach to Russian stress.
} 
(nominative plural svéči, genitive plural svečéj) mobile stress sets the nominative plural apart from the rest of the paradigm. What this shows is that stress can be analyzed as a morphological marker of well-behaved sets of inflectional features: the plural (as in patterns $\mathrm{c}-\mathrm{d}$ ), the oblique cases in the plural (as in pattern e) or the nominative plural (as in pattern f).

If we go back to a purely syntagmatic approach to Russian stress, and assume that the stress placement of an inflected word depends totally on the interplay of the morphemes of the word, we are not in a position to capture the generalizations about subparadigm uniformity and stress as a marker of inflectional features since under the syntagmatic approach there is no straightforward way to refer to the morphological paradigm. Moreover, a syntagmatic approach would lead us to expect a random distribution of inflected forms with stem stress and ending stress in the paradigm. In other words, one would expect to find words where stress jumps back and forth between the stem and the ending in the various inflected forms of the paradigm, e.g. as visualized in Figure 6. However, this prediction of the syntagmatic approach is not borne out by the facts; stress patterns of the type given in Figure 6 are not characteristic of CSR. There is strong synchronic and diachronic evidence that this is a systematic property of the Russian grammar that an adequate linguistic analysis should seek to capture. As for the synchronic analysis of CSR, Nesset (1994) gives evidence from psycholinguistic experiments with nonce words indicating that mobile stress patterns are part of speakers' mental grammars. With regard to diachronic evidence, the patterns in Figure 5 are the result of a series of analogical changes meticulously documented by Zaliznjak (1985: 168-188). In Old Rusian, the relationship between stress and inflectional features was much less straightforward (i.e. closer to the pattern in Figure 6), but the system has undergone regularization, which indicates that it is closely related to morphology.

\section{Unattested:}

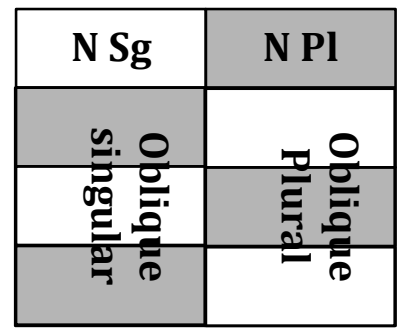

Figure 6: Unattested stress pattern with no straightforward connection between stress and inflectional features

The paradigmatic generalizations reviewed above pave the way for a morphological approach to the Russian stress system, whereby mobile stress is analyzed as a marker of inflectional features (plural, oblique cases plural, nominative plural) in the same way as inflectional endings are markers of number and case. This morphological approach has long traditions (see e.g. Zaliznjak's 1967 influential treatment), although the role of stress as a marker of inflectional features is often not made explicit (see, however, Nesset 1994 and 2015 for discussion). While the details of the morphological approach to Russian stress need not concern us here, it is important to notice that there is no need for trochaic feet in this 
approach. The stress placement of an inflected form of a word, say, the nominative plural mestá of mésto 'place', can be accounted for by a morphological rule, which changes the stress placement from the stem to the ending in the inflected form in question. There is no need to refer to a trochaic foot in such a rule, which therefore does not provide evidence in favor of trochaic feet.

Given that the Russian stress system is to a large extent morphologized, is it possible to tease apart the morphological (paradigmatic) aspects of the system from its purely phonological properties? One way to do that is to analyze stress in indeclinable words; since such words do not inflect, stress placement cannot be influenced by morphological factors (inflectional features). In order to circumvent the problem of morphological influence on stress and identify the default stress placement in Russian, Lavitskaya and Kabak (2014) carried out an experimental study of stress placement in indeclinable nouns. For the nonce words included in their experiment, they found that "stress in words ending in consonants is overwhelmingly final whereas in those ending in vowels, it is penultimate" (Lavitskaya and Kabak 2014: 376):

(12) a. C-final words: CVCV́C (final stress)

b. V-final words: CVCV́CV (penultimate stress)

As pointed out by Lavitskaya and Kabak (2014: 380), the pattern in (12b) can be analyzed as a trochaic foot built at the right edge of the word. In an attempt to provide a unified analysis of both patterns in (12), they propose an abstract underlying vowel at the end of words that are C-final on the surface (Lavitskaya and Kabak 2014: 380). This move enables them to assume a trochaic foot for both (12a) and (12b). Unfortunately, there does not appear to be much independent evidence for the postulated abstract vowel in C-final indeclinable words. For declinable words one could argue that a final abstract vowel /ъ/ in, say, stol-ъ 'table' is a marker of the morphological features nominative and singular and thus contrasts with overt endings such as /a/ in the genitive singular, / $\mathrm{u}$ / in the dative singular, etc. However, no such argument can be made for indeclinable words like barókko 'baroque'; since such words have the same form throughout the paradigm, one would have to accept a very abstract analysis, whereby all forms of the paradigm would have abstract endings that would never surface. It is hard to find any independent evidence for an analysis along these lines.

An alternative strategy for a unified analysis of $(12 a-b)$, which Lavitskaya and Kabak (2014) do not pursue, is to assume moraic trochees instead of syllabic trochees. ${ }^{19}$ Moraic trochees consist of two moras, while syllabic trochees unite two syllables. If we assign one mora to each vowel, and one mora to consonants in the syllable coda, we can reanalyze the patterns in (12a-b) as follows (each mora is marked with a subscript Greek $\mu$ ):

(13) a. C-final words: $\operatorname{CV}_{M}\left(\mathrm{CV́}_{\mu} \mathrm{C} M\right)$ (final stress)

b. V-final words: $\mathrm{CV}_{\mu}\left(\mathrm{CV} M \mathrm{M} C V^{\prime}\right)$ (penultimate stress)

${ }^{19}$ I am indepted to my colleague Julia Kuznetsova (p.c.), who pointed this out to me. 
As shown in (13), both C-final and V-final words display a right-aligned moraic trochee, which consists of two moras. Arguably, an analysis in terms of moraic trochees is somewhat unorthodox and speculative, and it raises the important question as to whether there is any independent evidence for coda moraicity in CSR. However, while this question is beyond the scope of the present study, it is clear that an analysis in terms of a right-aligned moraic trochee facilitates a unified analysis of Lavitskaya and Kabak's data-both C-final and V-final words. Even if one opts for a more traditional analysis based on syllabic feet and gives up a unified analysis of the patterns in (13a-b), it seems clear that (13b) involves a trochee headed by the penultimate syllable that carries stress. Regardless of which analysis one adopts, I conclude that CSR primary stress lends substantial support to a trochaic foot headed by the penultimate syllable that carries stress.

\subsection{Secondary stress and trochaic feet}

Arguments for rhythmic grouping of syllables, and hence for feet, come from secondary stress. In the following, we will see that secondary stress provides some evidence for trochaic feet, and hence further corroborates the conclusion from the previous section. However, Russian secondary stress is a somewhat understudied area and the facts are complex, which makes interpretation difficult. On the basis of a few isolated examples Revithiadou (1998: 123) makes a case for trochaic feet. For instance, she analyzes motopexota 'motorized infantry' in terms of two trochaic feet: (mòto)pe(xóta). Gouskova (2010) and Gouskova and Roon (2013) offer a thorough analysis of secondary stress in subordinating compounds consisting of two or more stems connected by "linking vowels". Consider the following examples (from Gouskova 2010; ' stands for primary stress and 'represents secondary stress):

(14) a. oborònosposóbnost' 'defense capability' (left stem with fixed stem stress, Zaliznjak's type a)

b. koràblestroénie 'ship building' (left stem with fixed ending stress, Zaliznjak's type b)

c. gòlovotjápstvo 'negligence' (left stem with mobile stress, Zaliznjak's type f)

According to Gouskova (2010) and Gouskova and Roon (2013), the left stems with fixed stem stress (Zaliznjak's type a, see Figure 5) receive secondary stress on the syllable that attracts stress in the corresponding full word. Thus, since oboróna 'defense' takes stress on the last syllable of the stem, this syllable receives secondary stress in oborònosposóbnost' in (14a). This does not offer an argument for any foot structure; the location of the stress is an idiosyncratic fact about the word/stem in question that language learners must acquire on an item-by-item basis. No phonological rule involving foot structure guides that learning process.

For left stems with fixed ending stress (Zaliznjak's type b, see Figure 5), on the other hand, secondary stress is introduced by a phonological rule, which according to Gouskova (2010) places stress on the stem-final syllable (see koràblestroénie 'ship building' in (14b)). This would be compatible with an analysis in terms of a trochaic foot comprising the syllable with secondary stress and the following 
"linking vowel", i.e. ko(ràble)stro(éni)e, although Gouskova, whose focus is not on foot structure, does not pursue such an analysis. The fact that the linking vowel strongly resists (secondary) stress (Gouskova 2010: 399) is compatible with an analysis where it is the non-head of a trochaic foot. The foot structure $k o(r a ̀ b l e) s t r o(e ́ n i) e$ thus captures that stress falls on the stem-final syllable /ra/, while the following syllable, which contains the linking vowel, cannot receive stress.

According to Gouskova (2010), left stems with mobile stress (e.g. golová 'head', which belongs to Zaliznjak's type f, see Figure 5) default to secondary stress on the word-initial syllable, as in gòlovotjápstvo 'negligence' in (14c). In order to capture this generalization one could assume a phonological rule that assign a trochaic foot to the left edge of the word, i.e. (gòlo)vo(tjápstvo).

In sum, even though the system is complex due to the interaction of several factors, it seems that secondary stress lends some support to trochaic feet.

\subsection{Trochees and iambs in "switch languages"}

Although the situation is far from clear, the Russian system of primary and secondary stress appears to provide at least some substantial evidence in favor of trochaic feet. This is at variance with the strong version of the trochee-iamb shift hypothesis in (8a), and at the same time leaves us with a seemingly contradictory picture, whereby vowel reduction employs iambs, while stress has trochees. However, there appear to be typological parallels from "switch languages", i.e. languages where both trochees and iambs are attested at the same time. For example, Houghton (2013), who relies on data from Dixon (1977 and 1981), analyzes the Australian languages Yidiny and Wargamay as "switch languages", where productive processes are sensitive to both trochaic and iambic feet. For example, according to Houghton (2013: 133) Yidiny has a reduplication rule, whereby a plural is created by reduplication of a foot. Importantly, if the root involves a trochaic foot, the domain of reduplication is a trochee, whereas an iamb is reduplicated for iambic roots. Thus, the plural of the trochaic (bú.na) 'woman' is (bú.na).(bú.na) with two trochaic feet (Houghton 2013: 141; parentheses refer to foot boundaries and full stops represent syllable boundaries). The plural of (mu.lá).ri 'initiated man', which involves an iambic foot followed by an unfooted syllable, is (mu.lá).(mu.lá).ri with two iambs before the unfooted final syllable. In view of the evidence adduced in sections 5.1 and 5.2 it does not seem far-fetched to analyze Russian as a "switch language", where vowel reduction involves iambs and stress placement trochees.

\section{Conclusion}

The contribution of the present study can be summarized as follows. First, we have seen that the jer shift can be analyzed in terms of a trochaic pattern, whereby jers fell unless they headed a foot. Second, the foot-based approach has been shown to be superior to the counting mechanism of the traditional version of Havlik's law, since the foot-based account avoids ad hoc stipulations and facilitates crosslinguistic comparison. Third, it has been argued that the jer shift was part of a trochee-iamb shift, in the sense that iambs succeeded trochees in the prosodic 
subsystem of vowel reduction. Fourth, while detailed analysis of the CSR prosodic system was beyond the scope of the present article, it has been suggested that CSR may be a "switch language" akin to Australian languages such as Yidiny and Wargamay, where productive processes are sensitive to both trochees and iambs. Finally, with regard to linguistic theory the present study has applied the UsageBased Model to historical phonology, and shown that the Usage-Based Model offers a straightforward account of prosodic change.

There emerge a number of implications for further study of the history of Russian, the synchronic analysis of modern Russian and linguistic theory. I have limited myself to discussing the fall and vocalization of the jers from the point of view of sound change and not explored the complex morphophonological processes that took the vowel zero alternations created by the jer shift and turned them into the system of mobile vowels in present day Russian. To what extent did these morphophonological processes interact with the foot structure of the language? As for modern Russian, the idea of Russian as a "switch language" calls for more empirical studies of the interaction of trochaic and iambic patterns in the prosodic system. Finally, with regard to linguistic theory we need more studies of the UsageBased Model as a theory of phonological change. Formal implementations of the principles of the model would be particularly welcome. However, these questions must be left for future research.

\section{References}

Albright, Adam. (2011) "Paradigms". Marc van Oostendorp, Colin J. Ewen, Elizabeth Hume and Keren Rice, eds. The Blackwell companion to phonology 4: Interfaces. Oxford: Basil Blackwell, 1972-2001.

Alderete, John. (1995) "Faithfulness to prosodic heads". Rutgers optimality archive, Report No. 94, http://roa.rutgers.edu/.

Andersen, Henning. (1972) "Diphthongization". Language 48.1: 11-50.

Andersen, Henning. (1973) "Abductive and deductive change". Language 49: 765793.

Andersen, Henning. (1996) Reconstructing prehistorical dialects: initial vowels in Slavic and Baltic. Berlin: Mouton de Gruyter.

Andersen, Henning. (1998) "Slavic". Anna Giacalone Ramat and Paolo Ramat, eds. The Indo-European Languages. London and New York: Routledge, 415-453.

Andreassen, Helene N. and Julien Eychenne. (2013) "The French foot revisited". Language Sciences 39: 126-140.

Barnes, Jonathan. (2006) Strength and weakness at the interface: positional neutralization in phonetics and phonology. Berlin: Mouton de Gruyter.

Bethin, Christina Y. (1998) Slavic prosody: Language change and phonological theory. Cambridge: Cambridge University Press.

Bethin, Christina Y. (2006) "Stress and tone in East Slavic dialects". Phonology 23.2: 125-156.

Bethin, Christina Y. (2010) “Perceptual salience in dialect contact: The okan'e/akan'e dialects of East Slavic". Journal of Slavic Linguistics 18.1: 7-54. 
Bethin, Christina Y. (2012a) "On paradigm uniformity and contrast in Russian vowel reduction". Natural Language and Linguistic Theory 30: 425-463.

Bethin, Christina Y. (2012b) "Effects of vowel reduction on Russian and Belarusian inflectional morphology". Lingua 122: 1232-1251.

Blumenfeld, Lev A. (2006) Constraints on phonological interactions. Ph.D. dissertation, Stanford University.

Burzio, Luigi. (1996) "Surface constraints versus underlying representation". Jacques Durand and Bernard Laks, eds. Current Trends in Phonology: Models and Methods. Salford: European Studies Research Institute, University of Salford Publications, 97-122.

Chomsky, Noam. (1964) Current issues in linguistic theory. The Hague: Mouton.

Chomsky, Noam. (1986) Knowledge of language. Its nature, origin, and use. Westport and London: Praeger.

Crosswhite, Katherine. (2001) Vowel reduction in Optimality Theory. New York and London: Routledge.

Dąbrowska, Ewa. (2004) Language, mind and brain: Some psychological and neurological constraints on theories of grammar. Edinburgh: Edinburgh University Press.

Dixon, Robert M. W. (1977) A grammar of Yidin. Cambridge: Cambridge University Press.

Dixon, Robert M. W. (1981) Wargamay. Robert M.W. Dixon and Barry J. Blake, eds. Handbook of Australian languages. Vol.2, Wargamay, the Mpakwithi dialect of Anguthimri, Watjarri, Margany and Gunya Tasmanian. Amsterdam: John Benjamins, 1-146.

Evans, Nicholas and Stephen C. Levinson. (2009) "The myth of language universals: Language diversity and its importance for cognitive science". Behavioral and Brain Sciences 32: 429-492.

Feldman, Jerome A. (2006) From molecule to metaphor: A neural theory of language. Cambridge, Massachusetts, and London, England: The MIT Press.

Fodor, Jerry A. (1983) The modularity of mind. Cambridge, Massachusetts and London, England: The MIT Press.

Galinskaja, Elena A. (2009) Istoričeskaja fonetika russkogo jazyka (2nd edition). Moscow: Izdatel'stvo moskovskogo universiteta.

Goldberg, Adele E. (2006) Constructions at work: The nature of generalization in language. Oxford: Oxford University Press.

Gouskova, Maria. (2003) Deriving economy: Syncope in Optimality Theory. Ph.D. dissertation: University of Massachusetts at Amherst.

Gouskova, Maria. (2010) "The phonology of boundaries and secondary stress in Russian compounds". The Linguistic Review 17.4: 387-448.

Gouskova, Maria and Kevin Roon. (2013) "Gradient clash, faithfulness, and sonority sequencing effects in Russian compound stress". Laboratory Phonology 4(2): 383-434

Grenoble, Lenore. (2012) "Contact and the development of the Slavic languages". Raymond Hickey, ed. The Handbook of Language Contact. New York: John Wiley \& Sons, 581-597. 
Halle, Morris. (1997) “On stress and accent in Indo-European”. Language 73.2: 275313.

Halle, Morris and William Idsardi. (1995) "General properties of stress and metrical structure". John A. Goldsmith, ed. The Handbook of Phonological Theory. Oxford: Blackwell, 403-443

Halle, Morris and Jean-Roger Vergnaud. (1987) An essay on stress. Cambridge, Massachusetts, and London, England: The MIT Press.

Hayes, Bruce. (1995) Metrical stress theory: Principles and case studies. Chicago and London: The University of Chicago Press.

Hock, Hans Henrich. (1988) Principles of historical linguistics. Berlin, New York and Amsterdam: Mouton de Gruyter.

Houghton, Paula. (2013) Switch languages: Theoretical consequence and empirical reality. PhD dissertation: Rutgers university. Available In Rutgers Optimality Archive at http://roa.rutgers.edu/.

Hyman, Larry M. (2008) “Universals in phonology”. The Linguistic Review 25, 83137.

Isačenko, A.V. (1970) "East Slavic morphophonemics and the treatment of the jers in Russian: A revision of Havlík's Law". International Journal of Slavic Linguistics and Poetics 13: 73-124.

Ito, Junko and Armin Mester. (2003) "Weak layering and word binarity". Takeru Honma, Masao Okazaki, Toshiyuki Tabata, and Shin-Ichi Tanaka, eds. A New Century of Phonology and Phonological Theory. A Festschrift for Professor Shosuke Haraguchi on the Occasion of His Sixtieth Birthday, 26-65.

Jacobs, Haike. (1992) "The interaction between syllable structure and foot structure in the evolution from Classical Latin to Old French". Christiane Laeufer and Terrell A. Morgan eds., Theoretical Analyses in Romance Linguistics. Amsterdam/Philadelphia: John Benjamins, 55-79.

Jakobson, Roman. (1929/1971) "Remarques sur l'èvolution phonologique du russe comparée à celle des autres langues slaves". Selected Writings, vol. 1. The Hague and Paris: Mouton, 7-116.

Jakobson, Roman. (1963/1971) “Opyt fonologičeskogo podxoda k istoričeskim voprosam slavjanskoj akcentologii”. Selected Writings, vol. 1. The Hague and Paris: Mouton, 664-689.

Jakobson, Roman and Morris Halle. (1964) "Tenseness and laxness". David Abercrombie, D. B. Fry, P.A.D. MacCarthy, N.C. Scott and J.L.M. Trim, eds. In honour of Daniel Jones. Papers contributed on the occasion of his eightieth birthday 12 September 1961. London: Longmans, 96-101.

Janda, Laura A. (2010) "Cognitive linguistics in the year 2010". International Journal of Cognitive Linguistics 1.1: 1-30.

Jusczyk, Peter W., Anne Cutler and Nancy J. Redanz. (1993) "Infants' preference for the predominant stress pattern of English words". Child Development 64: 675687.

Kavitskaya, Darya. (2002) Compensatory Lengthening: Phonetics, Phonology, Diachrony. New York and London: Routledge.

Kavitskaya, Darya. (2005) "Pitch accent and the phonologization of vowel length in Slavic". Steven Franks, Frank Y. Gladley and Mila Tasseva-Kurktchieva, eds. 
Formal Approaches to Slavic Linguistics 13. Ann Arbor: Michigan Slavic Publications.

Kenstowicz, Michael. (1997) “Quality-driven stress”. Rivista di Linguistica 9.1, 157187.

Kenstowicz, Michael. (2005) "Paradigmatic uniformity and contrast”. Laura Downing, T. Alan Hall, and Renate Raffelsiefen, eds. Paradigms in phonology. Oxford: Oxford University Press, 145-169.

Kiparsky, Valentin. (1963) Russische historische Grammatik (vol. 1). Heidelberg: Carl Winter Universitätsverlag.

Kiparsky, Valentin. (1979) Russian historical grammar. Ann Arbor, Michigan: Ardis.

Knjazev, Sergej V. (2000) “K voprosu o mexanizme vozniknovenija akan'ja v russkom jazyke". Voprosy jazykoznanija 1: 75-101.

Kumashiro, Fumiko. (2000) Phonotactic interactions: A non-reductionist approach to phonology. Ph.D. dissertation, University of California at San Diego.

Labrune, Laurence. (2012) "Questioning the universality of the syllable: Evidence from Japanese". Phonology 29: 113-152

Langacker, Ronald W. (1991) Concept, image, and symbol. Berlin and New York: Mouton de Gruyter.

Langacker, Ronald W. (2000) Grammar and conceptualization. Berlin and New York: Mouton de Gruyter.

Langacker, Ronald W. (2008) Cognitive Grammar: A basic introduction. Oxford: Oxford University Press.

Laver, John. (1994) Principles of phonetics. Cambridge: Cambridge University Press.

Lavitskaya, Yulia and Barıș Kabak. (2014) "Phonological default in the lexical stress system of Russian: Evidence from noun declension". Lingua 150: 363-385.

Matusevič, Margarita I. (1976) Sovremennyj russkij jazyk: fonetika. Moscow: Prosveščenie.

McCarthy, John J. (2005) “Optimal paradigms”. Laura Downing, T. Alan Hall, and Renate Raffelsiefen, eds. Paradigms in phonology. Oxford: Oxford University Press, 170-210.

McCarthy, John J. and Alan S. Prince. (1993) "Generalized alignment". Geert Booij and Jaap van Marle, eds. Yearbook of Morphology 1993, 79-153.

Mołczanow, Janina, Ulrike Domahs, Johannes Knaus, and Richard Wiese. (2013) "The lexical representation of word stress in Russian: Evidence from eventrelated potentials". The Mental Lexicon 8.2: 164-194.

Nathan, Geoffrey S. (2008) Phonology: A Cognitive Grammar introduction. Amsterdam/Philadelphia: John Benjamins Publishing Company.

Nesset, Tore. (1994) Russian Stress. Oslo: Novus Press.

Nesset, Tore. (2005) "Allomorphy in the Usage-Based Model: The Russian past passive participle". Cognitive Linguistics 16.1: 145-167.

Nesset, Tore. (2008) Abstract phonology in a concrete model: Cognitive linguistics and the morphology-phonology interface. Berlin and New York: Mouton de Gruyter.

Nesset, Tore. (2015) How Russian came to be the way it is. Bloomington, Indiana: Slavica Publishers. 
Prince, Alan, and Paul Smolensky. (2004) Optimality Theory: Constraint interaction in generative grammar. Oxford: Basil Blackwell. (Revision of 1993 technical report, Rutgers Center for Cognitive Science.)

Revithiadou, Anthi. (1998) Headmost accent wins: Head dominance and ideal prosodic form in lexical accent systems. The Hague: Holland Academic Graphics.

Rice, Curt. (2007) "The role of Gen and Con in modeling ternary rhythm". Patrik Bye, Sylvia Blaho and Martin Krämer, eds. Freedom of Analysis? Berlin and New York: Mouton de Gruyter, 233-255.

Salmons, Joseph, Robert Fox and Ewa Jacewicz. (2012) "Prosodic skewing of input and the initiation of cross-generational sound change". Maria-Josep Solé and Daniel Recasens, eds. The Initiation of Sound Change. Perception, production, and social factors. Amsterdam and Philadelphia: John Benjamins.

Selkirk, Elisabeth. (1995) "The prosodic structure of function words". Jill Beckman, Laura W. Dickey and Suzanne Urbanczyk, eds. Papers in Optimality Theory. (University of Massachusetts Occasional Papers 18). Amherst, Mass.: GLSA, 439469.

Shevelov, George Y. (1965) A Prehistory of Slavic: The Historical Phonology of Common Slavic. New York: Columbia University Press.

Steriade, Donca. (2000) "Paradigm uniformity and the phonetics-phonology boundary". Michael Broe and Janet Pierrehumbert, eds. Papers in laboratory phonology, V: Acquisition and the lexicon. Cambridge: Cambridge University Press, 313-334.

Švedova, Natalija Ju. (ed.) (1980) Russkaja grammatika vol. 1. Moscow: Nauka. Taylor, John R. (2002) Cognitive Grammar. Oxford: Oxford University Press.

Timberlake, Alan. (1983a) "Compensatory lengthening in Slavic 1: Conditions and dialect geography". Vladimir Markov and Dean S. Worth, eds. From Los Angeles to Kiev. Papers on the occasion of The Ninth International Congress of Slavists, Kiev, September, 1983. Columbus, Ohio: Slavica Publishers, 207-235.

Timberlake, Alan. (1983b) "Compensatory lengthening in Slavic 2: Phonetic reconstruction". Michael S. Flier, ed. American Contributions to the Ninth International Congress of Slavists, Kiev, September 1983. Vol. 1. Linguistics. Columbus, Ohio: Slavica Publishers, 293-319.

Veenker, Wolfgang .(1967) Die Frage des finnougrischen Substrats in der russischen Sprache. Bloomington: Indiana University Press.

Vlasto, Alexis P. (1986) A linguistic history of Russia to the end of the eighteenth century. Oxford: Clarendon Press.

Yearley, Jennifer. (1995) "Jer vowels in Russian”. Jill Beckman, Laura W. Dickey and

Suzanne Urbanczyk, eds. Papers in Optimality Theory. (University of Massachusetts Occasional Papers 18). Amherst, Mass.: GLSA, 533-571

Zaliznjak, Andrej A. (1967) Russkoe imennoe slovoizmenenie. Moscow: Nauka. Zaliznjak, Andrej A. (1985) Ot praslavjanskoj akcentuacii k russkoj. Moscow: Nauka. Zaliznjak, Andrej A. (2015) Drevnerusskoe udarenie. Obščie svedenija i slovar'. Moscow: Jazyki slavjanskoj kul'tury. 